\title{
Amenazas a la seguridad nacional derivada de crímenes que afectan al medio ambiente ${ }^{1}$
}

\author{
Andrés Hernando Matiz Rojas \\ Escuela Militar de Cadetes "General José María Córdova”
}

\begin{abstract}
Resumen. En el año 2018, el Plan Nacional de Desarrollo estableció una línea llamada "Biodiversidad y riqueza natural: activos estratégicos de la Nación". Dado que era la primera vez que un gobierno establecía dentro de su política de defensa y seguridad al medio ambiente como un interés principal de la nación, surgió la pregunta sobre cuáles delitos ambientales afectan la seguridad nacional. Es por esto que el objetivo de esta investigación buscó establecer de qué manera los crímenes que afectan el medio ambiente pueden ser una amenaza a la seguridad nacional. Para esto se empleó una metodología cualitativa descriptiva que incluyó la búsqueda de fuentes primarias de información y entrevistas a personal experto. De esta manera se encontró que los tres principales delitos que afectan la seguridad nacional son el narcotráfico, la minería ilegal y la deforestación, siendo esta última el resultado de las otras dos actividades ilícitas. Finalmente, se concluye que es importante ver y analizar de forma holística las amenazas y las problemáticas derivadas de los crímenes ambientales.
\end{abstract}

Palabras clave: biodiversidad; crimen; defensa nacional; medio ambiente; seguridad nacional.

1 Este capítulo forma parte de los resultados del proyecto de investigación "Medio ambiente y defensa nacional”, del Grupo de Investigación en Ciencias Militares de la Escuela Militar de Cadetes General José María Córdoba, registrado con el código COL0082556 de Minciencias. Los puntos de vista y los resultados que se presentan en este artículo pertenecen al autor y no reflejan necesariamente los de las instituciones participantes.

2 Ingeniero comercial. Doctorando en Estudios Internacionales de Paz, Conflicto y Desarrollo. Coordinador de Investigación de la Facultad de Ciencias Militares de la Escuela Militar de Cadetes “General José María Córdova”, Bogotá, D. C., Colombia. Orcid: https://orcid.org/0000-0001-6801-9064- Contacto: andres.matiz@esmic.edu.co 


\section{Introducción}

Según las estadísticas, Colombia es el segundo país más megadiverso del mundo y según la Cancillera (s. f.), "es el país más biodiverso por kilómetro cuadrado y cuenta con cerca del $14 \%$ de la biodiversidad del planeta, lo que convierte al país en un actor clave en el escenario de la diversidad biológica mundial" (Parr. 1).

Para entender esta referencia es necesario conocer el lugar que tiene Colombia frente a otros países en materia de biodiversidad (tabla 1):

Tabla 1. Lugar que ocupa la biodiversidad de Colombia en el mundo

\begin{tabular}{|c|c|c|c|c|c|c|c|}
\hline \multicolumn{4}{|c|}{ Fauna } & \multicolumn{4}{|c|}{ Flora } \\
\hline Lugar & Especie & $\begin{array}{l}\text { Registradas } \\
\text { a 2020-1* }\end{array}$ & $\begin{array}{c}\text { Endémicas** } \\
\text { a 2020-1 }\end{array}$ & Lugar & Especie & $\begin{array}{c}\text { Registradas } \\
\text { a 2020-1 }\end{array}$ & $\begin{array}{c}\text { Endémicas } \\
\text { a 2020-1 }\end{array}$ \\
\hline Primer & Aves & 1.999 & 82 & Primer & Orquídeas & 3.179 & \\
\hline Segundo & Anfibios & 849 & 375 & Segundo & Plantas & 26.232 & 6.206 \\
\hline Segundo & Mariposas & 4.059 & 350 & Tercero & Palma & 311 & 47 \\
\hline Segundo & $\begin{array}{c}\text { Peces } \\
\text { dulceacuícolas }\end{array}$ & 1.439 & 392 & & & & \\
\hline Tercero & Reptiles & 743 & & & & & \\
\hline Sexto & $\begin{array}{c}\text { Mamíferos } \\
\text { terrestres }\end{array}$ & 520 & 58 & & & & \\
\hline
\end{tabular}

* Esta información muestra la cantidad de especies registradas a corte 31 de diciembre de 2019.

** Las especies endémicas forman parte de la columna de especies registradas.

Fuente: Elaboración propia con base en datos del Sistema de Información sobre Biodiversidad de Colombia.

Es importante señalar que los datos de la tabla anterior corresponden solamente a la fauna y la flora continental, pues por falta de presupuesto no se han realizado investigaciones con la misma frecuencia e intensidad en el área marina del país, lo cual podría elevar las estadísticas de biodiversidad.

Además de la fauna y la flora, el Banco Mundial (2015) señala que Colombia es el tercer país con más agua dulce del mundo (Parr. 4) y que cuenta 
con diferentes ecosistemas, que se dividen entre bosques tropicales, sabanas, desiertos, páramos, manglares, arrecifes coralinos y pastos marinos (Ministerio de Ambiente y Desarrollo Sostenible, s. f., Parr. 1). Según la Cancillería de Colombia (s. f.), esto ha llevado a reconocer que la riqueza biológica representa una herramienta única para el desarrollo económico y social a largo plazo, así como para la erradicación de la pobreza. Además, la biodiversidad contribuye globalmente a la oferta de bienes y servicios ambientales (Parr. 1).

De lo anterior podemos inferir que con el reconocimiento del Estado de la riqueza biológica y de los ecosistemas del país como una herramienta de desarrollo se está apuntando al cumplimiento de los Objetivos de Desarrollo Sostenible, los cuales fueron adoptados por los líderes mundiales para erradicar la pobreza, proteger el planeta y asegurar la prosperidad para todos como parte de una nueva agenda de desarrollo sostenible (Organización de las Naciones Unidas [ONU], s. f., Parr. 1), lo cual denota la importancia para el país de cuidar el medio ambiente, al menos de iure.

Pese a lo anteriormente descrito, en Colombia se presentan diferentes delitos ambientales y otros que afectan directamente los ecosistemas y su fauna y flora, pero que, sin embargo, no son considerados delitos ambientales: la usurpación, el tráfico de estupefacientes y otras infracciones; delitos contra la seguridad pública; delitos contra la salud pública; delitos contra personas y bienes protegidos por el derecho. Sin importar si el delito afecta de iure o de facto, ambos presentan una amenaza a la seguridad nacional.

En esta investigación se tomó el concepto de seguridad nacional de Makinda (1998, citado por ONU, s. f.), quien la explica como "la preservación de las normas, reglas, instituciones y valores de la sociedad”. Sostiene además que todas las instituciones, principios y estructuras asociados con la sociedad, incluido su pueblo, deben ser protegidos de "amenazas militares y no militares" (Parr. 2). En Colombia, particularmente, estos delitos son cometidos por grupos armados organizados, grupos armados organizados residuales, grupos delictivos organizados y delincuencia común.

Si bien los grupos delictivos organizados y la delincuencia común no se consideran una amenaza militar, los grupos armados organizados y los grupos armados organizados residuales sí. Precisamente, el ítem VII de la Directiva 
0015 del Ministerio de Defensa Nacional (2016), mediante la cual se expiden los lineamientos del Ministerio de Defensa Nacional para caracterizar y enfrentar a los Grupos Armados Organizados (GAO), los define como grupos que

bajo la dirección de un mando responsable, ejerzan sobre una parte del territorio un control tal que les permita realizar operaciones militares sostenidas y concertadas. [...] Que use la violencia armada contra la Fuerza Pública u otras instituciones del Estado, la población civil, bienes civiles o contra otros grupos armados. (p. 5)

Teniendo en cuenta la importancia de la biodiversidad del país y los actores que amenazan la seguridad nacional, el Plan Nacional de Desarrollo 2018-2022 establece en su capítulo 4 una línea llamada "Biodiversidad y riqueza natural: activos estratégicos de la nación”. Esta es la primera vez que un plan de desarrollo incluye al medio ambiente, el agua y la biodiversidad como un interés principal de la nación, el cual hay que proteger. Por esta razón, la defensa de estos también quedó establecida en la Política de Defensa y Seguridad 2018-2022, la cual establece:

La riqueza natural de Colombia es enorme, pero el ritmo de destrucción es mayor. Somos una potencia en agua, biodiversidad y medio ambiente; el país ocupa en el mundo el segundo lugar en biodiversidad; el $10 \%$ de la fauna y la flora del mundo está en el 0,7 \% de la extensión terrestre que ocupa la nación. Tenemos 2,4 millones de hectáreas de páramos, cinco vertientes hidrográficas, acceso a dos océanos y compartimos la Amazonia, el principal pulmón del mundo. Tales recursos son activos estratégicos para el país y constituyen un factor central del poder nacional. Identificar como principal interés nacional tales activos estratégicos convierte en un asunto de seguridad su protección y preservación ante intereses foráneos y la acción depredatoria del narcotráfico, la extracción ilícita de minerales y la deforestación. (pp. 13-14)

En este caso, el gobierno nacional prioriza la lucha con dos delitos ambientales de iure y uno de facto, por ser considerados una amenaza a la seguridad nacional y en los cuales están involucrados grupos armados organizados, grupos armados organizados residuales y grupos delictivos organizados, que

3 Esta definición también ayuda a sustentar por qué se escogió este concepto de seguridad 
afectan significativamente el medio ambiente al realizar su accionar criminal. Si bien esto es un gran avance en la política de protección ambiental nacional, existen otros delitos perpetrados por estos grupos y la delincuencia común que también amenazan la seguridad nacional, aunque no existen datos sobre su impacto ambiental. Este escenario lleva a formular la siguiente pregunta: ¿Cuáles delitos ambientales afectan la seguridad nacional?

Es por esto que esta investigación busca establecer cómo los crímenes que afectan el medio ambiente pueden ser una amenaza a la seguridad nacional. De esta manera se espera hacer un aporte que fortalezca la política pública que responda a estas problemáticas.

\section{Metodología}

La metodología utilizada en la investigación fue cualitativa descriptiva. A partir de fuentes de información primaria y secundaria en bases de datos e informes institucionales se estableció cuáles grupos delictivos y cuáles crímenes afectan directa e indirectamente al medio ambiente. También se realizaron entrevistas semiestructuradas a personal de la Policía Nacional, el Ejército Nacional y a expertos en seguridad y medio ambiente sobre las amenazas a la seguridad nacional que pueden derivar de estos delitos.

\section{Resultados}

Los tres principales delitos que tiene en cuenta la Política de Defensa y Seguridad son el narcotráfico, la minería ilegal y la deforestación, siendo esta última el resultado de las otras dos actividades ilícitas. En el caso del narcotráfico, respecto a la siembra de cultivos ilícitos la Oficina de las Naciones Unidas contra la Droga y el Delito (UNODC, 2020) reportó 154.000 hectáreas de coca cultivadas (p. 1), lo cual se traduce en 462.000 hectáreas de bosque deforestados, según la información de la Dirección Nacional de Estupefacientes (2004), la cual ha establecido que para implementar una hectárea productiva de coca los cultivadores tienen que destruir tres (3) hectáreas de bosque (p. 3).

Esto tiene grandes repercusiones en el ecosistema. Como explica el ministro de Ambiente y Desarrollo Sostenible, Ricardo Lozano (Ministerio 
de Ambiente y Desarrollo Sostenible, s. f.), esta deforestación asociada a los cultivos de coca tiene impactos relacionados con la pérdida y migración de la fauna y flora de estos bosques, pérdida de estos suelos y aumento de la erosión y la desertificación, así como el consecuente incremento de deslizamientos, avalanchas y demás desastres asociados en el país (Parr. 3). Esto no solo se traduce en la destrucción de recursos genéticos, sino también en una afectación a las comunidades aledañas, las cuales se pueden ver afectadas por las sustancias utilizadas para el procesamiento del clorhidrato de cocaína, como son la soda cáustica, el ácido sulfúrico, el amoniaco, el metabisulfito de sodio, el acetato de etilo, entre otros, cuyos desechos terminan siendo lanzados a las fuentes hídricas, lo que causa graves problemas de salud o al suelo, pues produce su acidificación.

Por otra parte tenemos la minería ilegal. De acuerdo con los informes de la Defensoría del Pueblo (2015), 16.701 hectáreas han sido deforestadas por la minería ilegal, es decir que esta actividad fue la causante del 13,8 \% de la deforestación en los años 2013 y 2014 (p. 181). Aunque esta cifra no distingue si el tipo de minería ilegal es aluvión o en socavón, resulta claro que además de la afectación al suelo y a las especies de fauna y flora que habitaban estos territorios, también se afecta de manera directa el subsuelo, lo cual impide la recuperación del ecosistema a corto y mediano plazo. Aunado a esta destrucción se encuentra la utilización de químicos como el mercurio y el cianuro, empleados en el proceso de amalgamación.

Según información de la Dirección de Carabineros de la Policía Nacional (2017; citado por Rubiano, 2019), el mercurio es el insumo más utilizado en Colombia: de las 118,8 toneladas de mercurio que ingresan legalmente al país cada año, al menos el $50 \%$ se desvía hacia la minería ilegal (p. 14). Este dato es importante tenerlo en cuenta, ya que el Departamento Nacional de Planeación (2016; citado por Rubiano, 2019) explica que el $86 \%$ de la producción de oro nacional proviene de extracción ilícita de minerales, caracterizada por el uso de mercurio: "Se estima que 75 toneladas de mercurio son liberadas anualmente a causa de la minería de oro. Colombia es el segundo país que más mercurio libera después de China” (Rubiano, 2019, pp. 3-4). Por lo general, este mercurio se libera en las fuentes hídricas o al ambiente durante la quema de amalgamas (Ministerio de Minas y Energía, 2014), 
que posteriormente se precipita con la lluvia sobre los suelos circundantes como mercurio divalente $(\mathrm{Hg} 2+)$; una vez allí, en la superficie del suelo se da el paso de $\mathrm{Hg} 2+$ a $\mathrm{Hg} 0$ emitiendo mercurio gaseoso. Adicionalmente, el mercurio sufrirá procesos de fotorreducción que también aportarán mercurio gaseoso. [...] donde la contaminación pasa por la introducción de este metal en la cadena trófica. (p. 15)

Este tipo de contaminación derivado de la minería afecta tanto a la fauna como a los humanos, ya sea por la ingesta de agua o de carne contaminada, lo que deriva en grandes problemas, como la enfermedad de Minamata, la cual está asociada al envenenamiento por mercurio.

Si bien Colombia ha avanzado en la lucha contra delitos como el narcotráfico y la minería ilegal, para lo cual ha creado grupos especializados tanto en el Ejército Nacional como en la Policía Nacional, no había promulgado una política igual de fuerte para luchar contra los grupos ilegales dedicados a la deforestación, ya que esta se tomaba como efecto derivado de las dos actividades ilícitas anteriores.

Las estadísticas con que cuenta Parques Nacionales Naturales de Colombia (2020) mencionan 197.159,31 hectáreas deforestadas en el país (p. 19). De acuerdo con Grau y Aide (2008; citado por Fedesarrollo, s. f.), una de las principales causas de este fenómeno es la ganadería extensiva, que representa casi el $60 \%$ de la deforestación del país. Esto incluye tanto a las personas que mantienen ganado con fines productivos, como a aquellas que buscan asegurar la tenencia de la tierra mediante la introducción de ganado en pie (p. 5). Si bien este factor no muestra un halo de ilegalidad a simple vista, lo que se esconde es totalmente diferente: según la Revista Agrollanos (2017), el director de la Corporación para el Desarrollo Sostenible del Norte y el Oriente Amazónico (CDA), César Humberto Meléndez, afirma que “tumbar una hectárea de bosque y sembrar pasto vale más de dos millones de pesos. El que tumba cien hectáreas, entonces, debe tener doscientos millones para hacerlo en poco tiempo. Ese dinero no lo tienen los campesinos" (Parr. 4). Esto muestra tanto la ilegalidad de quien paga ${ }^{4}$, como la de los grupos que realizan

4 Actualmente, para el aprovechamiento forestal es necesario contar con el permiso de la Autoridad Nacional de Licencias Ambientales (ANLA), después de cumplir con diferentes requisitos como 
la deforestación, dentro de los cuales se han encontrado grupo armados organizados residuales, como lo indica la Fiscalía General de la Nación (2020):

Como parte de la estrategia institucional contra la deforestación en la Amazonia colombiana y en su propósito de adelantar acciones judiciales para garantizar la protección de los recursos naturales, la Fiscalía General de la Nación prorrogó las órdenes de captura contra tres cabecillas de los Grupos Armados Organizados Residuales (GAOR) que serían los responsables de arrasar con miles de hectáreas de selva en una zona de reserva forestal en el sur oriente del país. (Parr. 2)

El tráfico ilegal de madera es la otra causa principal de la deforestación en el país, ya que según estimaciones del Ministerio de Ambiente y Desarrollo Sostenible (s. f.; citado en Environmental Investigation Agency, 2019), el $47 \%$ de la madera que se vende en Colombia es ilegal, lo cual muestra que la mayoría de madera traficada ilegalmente es vendida en el mercado interno. Esto evidencia la falta de controles respecto al seguimiento de las autoridades ambientales correspondientes, siendo los territorios más afectados por esta práctica ilegal el pie de monte amazónico. Respecto a los autores de este delito, se cree que es realizado por grupos delictivos organizados, ya que a la fecha no se ha evidenciado participación de grupos armados organizados o grupos armados organizados residuales. Específicamente, en estos tres delitos se identifican diferentes grupos armados organizados o grupos armados organizados residuales en todo el territorio nacional (figura 1).

Estos grupos se encuentran distribuidos en todo el país y los delitos que cometen por lo general tienen una gran afectación ambiental derivada de otros tipos de delitos (figura 2), como los delitos contra la seguridad pública, en cuanto a las masacres y ajustes de cuentas. De los delitos contra la salud pública, cuando arrojan químicos en las fuentes de agua o el suelo, lo cual afecta las comunidades y la fauna. Delitos contra personas y bienes protegidos por el derecho mediante la deforestación, con la cual se adueñan de territorios del Estado.

el estudio técnico que demuestre una mejor aptitud del uso del suelo diferente al forestal, permisos con los que no cuentan y estudios que no realizan. 


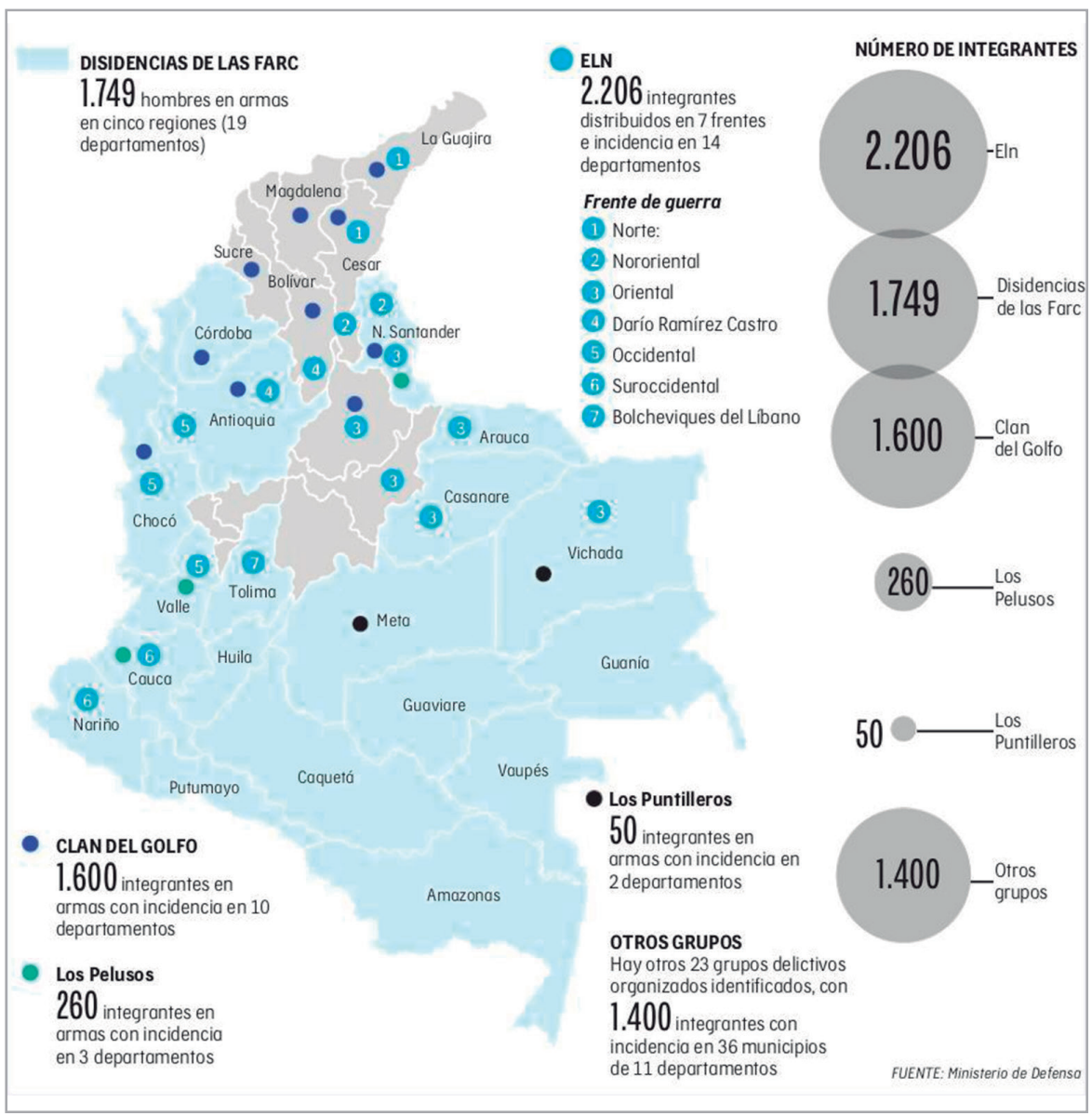

Figura 1. Grupos armados organizados y grupos delictivos organizados en Colombia.

Fuente: Ministerio de Defensa (2018).

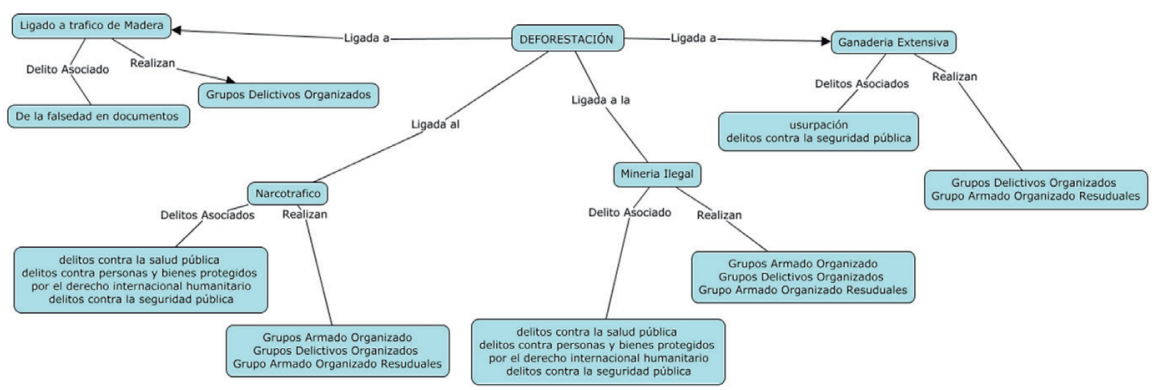

Figura 2. Amenazas a la seguridad derivadas de crímenes ambientales. Fuente: Elaboración propia. 


\section{Discusión}

Por lo general, cuando se exponen los temas de narcotráfico y minería ilegal siempre se habla de los impactos económicos, sociales y de seguridad que estos flagelos dejan a corto plazo, pero no se tienen en cuenta sus implicaciones ambientales a mediano y largo plazo. Esto puede generar diversos tipos de conflictos económicos, sociales y de seguridad, como consecuencia de que no haya tierras donde cultivar para asegurar la seguridad y la soberanía alimentaria de las comunidades. Por otra parte, también incide en el aumento de las enfermedades que causan los químicos utilizados para la elaboración del clorhidrato de cocaína y la amalgamación del oro, así como en la pérdida de fauna de alto valor estratégico debido al envenenamiento por metales pesados y la migración debido a la destrucción del hábitat.

En este sentido, analizar los delitos asociados permite determinar las amenazas, tales como el desplazamiento forzado, el control territorial por parte de grupos armados organizados precursores de grupos paramilitares y guerrillas que no se acogieron a los acuerdos de paz realizados con estos. Esto genera la impresión de que el conflicto armado interno en Colombia sigue y de que solamente hubo un cambio de actores armados ilegales, que siguen afectando de la misma forma al medio ambiente y las comunidades rurales.

En el caso de la ganadería extensiva se observa la diversificación de actividades delictivas de estos dos grupos ilegales. Específicamente, se evidencia el delito de la usurpación de tierras y de agua, algo que ha venido afectando los parques naturales nacionales y los resguardos indígenas. Además, algunas de estas tierras fueron usurpadas a víctimas del conflicto armado interno, lo que ha dificultado el proceso de restitución de tierras.

Respecto al tráfico de madera cabe señalar que la falta de control por parte de las autoridades ambientales, acompañada por la falsificación de documentos, permiten que barcos y camiones cargados con madera viajen tranquilamente desde el pie de monte amazónico y el chocoano mediante transporte multimodal hasta llegar al interior del país sin problema alguno. 


\section{Conclusiones}

Si bien el Estado colombiano asoció ciertas amenazas ambientales a la seguridad nacional, no había dado presupuesto para que la Fuerza Pública y la Fiscalía actuaran frente a estas, de manera que las investigaciones se realizaban priorizando los objetivos de seguridad y defensa del gobierno de turno. Ahí radica la importancia de incluir al medio ambiente como un objetivo estratégico en la Política de Defensa y Seguridad Nacional.

Es importante ver y analizar de forma holística las amenazas y las problemáticas derivadas de los crímenes ambientales, ya que su afectación no solo se limita a un daño a los ecosistemas, sino que también incide negativamente en el estilo de vida de las comunidades en términos de salud, economía y seguridad.

Si bien en los últimos años la preocupación por el medio ambiente ha ido en aumento, no se ha hecho una defensa integral que tenga en cuenta todos los factores, tanto legales como ilegales, que lo afectan.

\section{Referencias}

Banco Mundial. (2015, marzo 10). Brasil, Colombia y Perú, entre los que más agua tienen en el mundo. https://www.bancomundial.org/es/news/feature/2015/03/10/brasil-colombiaperu-paises-mas-agua-tienen-en-el-mundo

Cancillería de Colombia. (s. f.). Biodiversidad. https://www.cancilleria.gov.co/internacional/ politica/ambiental/biodiversidad

Defensoría del Pueblo. (2015). La minería sin control: Un enfoque desde la vulneración de los Derechos Humanos. https://www.defensoria.gov.co/public/pdf/InformedeMinerIa2016.pdf

Departamento Nacional de Planeación. (2016). Dividendos ambientales de la paz. https://colaboracion.dnp.gov.co/CDT/Prensa/Presentaciones/Dividendo\%20Ambiental\%20de $\% 20$ la\%20Paz\%20FINAL\%202016-03-16.pdf

Departamento Nacional de Planeación. (s. f.). Pacto por la sostenibilidad: Producir conservando y conservar produciendo. En Plan Nacional de Desarrollo 2018 - 2020. https://colaboracion.dnp.gov.co/CDT/Prensa/Presentaci\%C3\%B3n\%20PND\%20Sostenibilidad.pdf

Dirección Nacional de Estupefacientes. (2004). Los cultivos ilícitos en Colombia. Subdirección de Asuntos Regionales y Erradicación.

Environmental Investigation Agency. (2019). Condenando el bosque: Ilegalidad y falta de gobernanza en la Amazonia colombiana. https://content.eia-global.org/posts/documents/000/000/894/original/Condenando_el_Bosque.pdf?1561565558 
Fedesarrollo. (s. f.). Deforestación en Colombia: retos y perspectivas. https://pdfs.semanticscholar.org/64e3/e658271cb0c008a87ab3176079b7e9a51b66.pdf

Fiscalía General de la Nación. (2020). Fiscalía logra órdenes de captura contra cabecillas de grupos residuales por deforestación en zona de especial protección ambiental. https:// www.fiscalia.gov.co/colombia/noticias/fiscalia-logra-ordenes-de-captura-contra-cabecillas-de-grupos-residuales-por-deforestacion-en-zona-de-especial-proteccion-ambiental/

Ministerio de Ambiente y Desarrollo Sostenible. (s. f.). Minambiente llamó la atención sobre impactos de cultivos ilícitos en bosques de Colombia. https://www.minambiente.gov.co/ index.php/noticias/4264-minambiente-llamo-la-atencion-sobre-impactos-de-cultivos-ilicitos-en-bosques-de-colombia\#:- :text=Entre\%202016\%20y\%202017\%20se,deforestaci\%C3\%B3n\%20causada\%20por\%20cultivos\%20il\%C3\%ADcitos. \&text=El\%20 impacto $\% 20 \mathrm{a} \% 20$ nuestros\%20Parques,por\%20los $\% 20$ cultivos $\% 20 \mathrm{de} \% 20$ coca

Ministerio de Ambiente y Desarrollo Sostenible. (s. f. ). 10 ecosistemas para enamorarse de Colombia. https://www.minambiente.gov.co/index.php/noticias/4711-10-ecosistemas-para-enamorarse-de-colombia

Ministerio de Defensa Nacional. (2016, abril 22). Directiva 0015. Asunto: Expedir los lineamientos del Ministerio de Defensa Nacional para caracterizar y enfrentar a los Grupos Armados Organizados (GAO). https:/www.mindefensa.gov.co/irj/go/km/docs/ Mindefensa/Documentos/descargas/Prensa/Documentos/dir_15_2016.pdf

Ministerio de Defesa Nacional. (2018). Politica de defensa y seguridad. https://www.mindefensa.gov.co/irj/go/km/docs/Mindefensa/Documentos/descargas/Prensa/Documentos/ politica_defensa_deguridad2019.pdf

Ministerio de Minas y Energía. (2014). Estudio de la cadena del mercurio en Colombia con énfasis en la actividad minera de oro (t. 2). http://www.upme.gov.co/SeccionMineria_ sp/cadena_de_mercurio/Cadena_Mercurio_Tomo_II.pdf

Oficina de las Naciones Unidas contra la Droga y el Delito [UNODC]. (2020). Las hectáreas de coca bajaron, pero la producción de cocaína sigue en la parte alta de la serie histórica. https://www.unodc.org/documents/colombia/2020/Julio/Resumen_Ejecutivo_2019.pdf

Organización de las Naciones Unidas [ONU]. (s. f.). National Security versus Global Security. https://www.un.org/en/chronicle/article/national-security-versus-global-security

Parques Nacionales Naturales. (2020). Cifras de monitoreo de bosques IDEAM para las Áreas Protegidas del SPNN 1990-2020. https://www.parquesnacionales.gov.co/portal/wp-content/uploads/2021/09/cifras-monitoreo-de-bosques-ideam-para-spnn-2020.pdf

Revista Agrollanos. (2017). Un campesino no tiene 2 millones para tumbar una hectárea de bosque. https:/www.revistaagrollanos.com/2019/05/29/un-campesino-no-tiene-2-millones-para-tumbar-una-hectarea-de-bosquel

Rubiano, (2019). El mercurio en la minería ilegal de oro en los países del Bioma Amazónico: Diagnóstico de flujos comerciales, información científica y respuestas institucionales. https://www.gaiaamazonas.org/uploads/uploads/books/pdf/Informe_Hg_FGA_ RAISG_-_con_mapas.pdf 